\title{
Ethical issues in obesity interventions for populations
}

\section{Craig L. Fry}

Health Ethics and Policy, Murdoch Childrens Research Institute

Email: craig.fry@mcri.edu.au

\begin{abstract}
Beyond the usual technical and evidentiary considerations, there are ethical questions that we must consider in the justification of our obesity interventions in the name of expected population health gains. These relate to the types of health identities that are permitted in society, the possible unintended consequences of preferencing certain health identities over others, and the manner in which public health policies and interventions are justified. The prevalence of overweight and obesity in Australia highlights some of the areas of uncertainty and identifies some important ethical questions that arise as a result of this uncertainty. I propose that the Australian obesity prevention strategy could be evaluated using the Nuffield Council on Bioethics stewardship model of public health to assess whether any current approaches exceed recommended intervention constraints or limits. My aim is to prompt further debate on this topic.
\end{abstract}

A recurrent challenge for public health professionals is making research, policy and practice decisions in an environment where there is often tension between what can be done and what should be done in the name of health. In public health, this dilemma is typically defined as a question of how to apply our health-improving technical capabilities in line with best science, evidence and economics (efficiencies, resource rationing, waste prevention).

In essence, what is at issue is how to justify intervening in the lives of some individuals or groups in the pursuit of better health outcomes for the whole population. ${ }^{1}$ There are important technical and evidentiary considerations here such as defining the health problem, identifying available tools and resources and deciding what works best in preventing or alleviating the health impact. However, our health policy and intervention decisions are not wholly determined by science, evidence, technical expertise and knowledge. In many areas of population health, our policy and intervention decisions (and indeed the community attitudes and responses to these decisions) are also informed by a range of value positions about the 'types' of healthy citizens we wish to see in our societies.

These ideas about health types or identities fall somewhere along the theoretical continuum of positions described by individualist or collectivist frameworks - the libertarian, liberal, utilitarian and communitarian 'isms'. How we define health identity and where we are situated on this individualist-collectivist continuum comes down to what we believe about the nature of individual agency and responsibility (e.g. human rationality and the capacity to make 'good' choices around the consumptions and behaviours associated with health or otherwise), and the acceptability of different categories of individual actions according to their impacts and costs (individual and societal).

In lay terms, we can think of these health types or identities in two ways. Firstly, there are permissible or accepted health identities such as being rational and responsible, disciplined and in control, and aspiring to be healthy or healthier e.g. health seeking behaviour in pursuit of being fitter, thinner, smarter, stronger or faster. In the health sphere it is also acceptable to be vulnerable and in need of professional help. Secondly, there are the disapproved or contested health identities or states including being unhealthy, over-consumptive (of alcohol, drugs, food), non-adherent or out of control in the treatment context and engaging in health risks. ${ }^{1,2}$

These groupings of accepted and contested health identities are readily observable in the specialty public health fields concerned with drugs, alcohol, tobacco, food, gambling, sex, and other dangerous consumption activities with defined health risks. ${ }^{3}$ The value positions underpinning these health fields are, however, not always made explicit in either the public, academic or government debates on these issues.

The questions of whether, and how, different health identities are defined as accepted or contested are ethically relevant because they become the basis for the ways in which we perceive, understand and respond to what people do and experience in pursuit of good health (or otherwise). 
Population health policies and programs are crucial for the promotion of good health and prevention of avoidable health risks and harms across the individual, group and environment level. However, the inherent inequities that exist in the population level distributions and determinants of health, and the heterogeneity of understandings and practices of health require that we examine the values and ethical questions that exist in this area.

Health promotion strategies which emphasise the 'moral management of the self' (i.e. the responsibility to make healthy or accepted choices), can lead to punitive consequences for those who make unhealthy or contested choices. ${ }^{4}$ This paper examines concerns about targeting individuals versus population level interventions, given the lack of compelling evidence about the effectiveness of many interventions for reducing obesity.

\section{The problem of overweight and obesity}

The prevalence of overweight (a body mass index (BMI) above $25 \mathrm{~kg} / \mathrm{m}^{2}$ ) and obese (BMI above $30 \mathrm{~kg} / \mathrm{m}^{2}$ ) Australian adults and children has increased significantly over the last 2 to 3 decades. ${ }^{5,6}$ In 2009 the National Preventive Health Taskforce Obesity Working Group highlighted the significant mortality, morbidity and financial impact on the population of high body mass in this country. ${ }^{7}$

Overweight and obesity is now regarded as one of the greatest public health challenges confronting Australia and many other industrialised countries, ${ }^{7}$ with the escalating epidemic of adult obesity estimated at more than 1 billion worldwide. ${ }^{8} \mathrm{~A}$ compelling case exists for intervening in overweight and obesity to the extent that doing so will deliver improved individual and public health, informed health choices and reduced societal costs. ${ }^{9}$

However, obesity is a complex public health problem that is controversial and challenging in a number of ways. First, there is debate about the utility of attributing purported causative factors for obesity, and the question of whether it is a disease in itself or a risk factor for other chronic diseases. ${ }^{10}$

Second, there is uncertainty about the best intervention approaches, whether these are focused at the population level (e.g. policy and regulation/taxation/financial disincentives; food labelling/nutritional information; advertising restrictions; social marketing/mass media/education and prevention; physical activity infrastructure and urban environment; workforce), or the level of the individual (e.g. commercial dieting; tailored fitness programs; surgery/ gastric banding; nutrigenomics/personalised approaches to obesity prevention). ${ }^{11}$

Despite the existence of a wide range of population and individual-focused interventions, the available evidence regarding effectiveness in preventing obesity is equivocal. ${ }^{12}$
Thomas and colleagues concluded recently that at present there is only limited evidence to support [individual and population level] interventions that lead to long-term sustained change in health and behaviour regarding obesity. ${ }^{13}$

The complexity of the problem of overweight and obesity requires multifaceted solutions. In the context of an increasingly rationed health dollar, and uncertain evidence about the long-term impact of obesity interventions, important ethical considerations arise around access to preventive programs and treatments ${ }^{14}$ and the justification for intervening in the lives of certain individuals in the population.

\section{Ethical considerations}

Overweight and obesity measurement and monitoring are new frontiers of public health surveillance, with significant policy efforts directed at frameworks for monitoring both individuals and population target groups. ${ }^{7,15}$ The policy documents make clear the roles and responsibilities involved:

\section{All Australians share responsibility for individual and population health, and the success of the health system. \\ It is the role of government to enable and support individuals, families and communities to take responsi- bility for health ('making healthy choices easier for everyone, everywhere and every day'). ${ }^{7}$}

In the case of obesity, there is therefore an expectation that governments and individuals should seek to minimise behaviours and choices that reduce good health and increase cost burdens on the health system.

Peckham and Hann have acknowledged that focusing on the responsibilities of overweight and obese individuals might be ethically justified if it did not add to the harm. ${ }^{16}$ But they also argue that a focus is needed on the moral questions surrounding a public health policy that rests on equivocal evidence, sustains the stigma against overweight and obese persons, and has a part to play in the causation of untold human misery. ${ }^{16}$

One such ethical question is the extent to which we consider in public health what the impact is of preferencing certain accepted health types or identities over contested health types. A common view about high profile health problems (e.g. mental illness, drug dependence, obesity) is that the primary affliction of those people experiencing such conditions is a type of disrupted agency in relation to their consumption or other health-related choices which affect their ability to lead the lives they value.

In the case of obesity, Peckham and Hann have observed that fatness is becoming increasingly stigmatised as 'scientific' health information is incorporated into a 
pre-existing set of cultural beliefs that fat people are either gluttonous or slothful (or both), and that their lack of selfcontrol and moral fibre is costing millions of pounds each year in medical treatment and lost earnings. ${ }^{16}$

The assumptions we make about the types of lives that afflicted groups value (or should do) guide the professional and policy choices about prevention, early intervention and treatment. In the case where such prevention target groups express a periodical preference for taking health risks (e.g. in the case of obesity - eating junk food or exercising less), these choices can unintentionally lead to further repression because these already vulnerable and marginalised groups are seen to be engaged in disapproved behaviours (or contested health choices) for which they need professional assistance in avoiding.

Another ethical issue then in this intervention area is the question of what obese individuals themselves perceive to be the overweight and obesity problem, and their attitudes about acceptable intervention responses. ${ }^{13}$ A recent qualitative interview study by Thomas and colleagues has provided empirical findings in this area. The Thomas study showed that obese adults support interventions that are non-commercial, non-stigmatising and designed to improve lifestyles (e.g. regulation, physical activity programs and public health initiatives), rather than promoting weight loss (e.g. diets and surgery). ${ }^{13}$

Others have taken the idea of consumer involvement and engagement further in relation to obesity policy, by arguing for its direct application in the evaluation of obesity interventions - the evaluation of interventions should involve a strong ethical dimension...consideration of the opinions of the people affected, who are subjected to interventions in ways that necessarily go beyond individual consent... interventions might also be assessed by how much they empower people-and especially those persons... who are otherwise often disempowered. ${ }^{17}$

Further still, in a recent ethical evaluation of 60 interventions and policies targeting overweight or obesity, ten Have and colleagues identified a number of potential ethical problems including: ${ }^{9}$

- uncertain or unfavourable intervention effects on physical health

- negative psychosocial consequences (e.g. uncertainty, fears and concerns, stigmatisation, discrimination; enhanced inequalities)

- disregard for the social and cultural value of eating

- privacy concerns

- disregard for the complexity of responsibilities regarding overweight

- interventions infringe upon personal freedom regarding lifestyle choices and raising children, private enterprise, policy choices by schools and other organisations.
The authors concluded that an ethical framework to support decision makers in balancing potential ethical problems against the need to do something would be helpful. ${ }^{9}$

\section{The Nuffield Council on Bioethics stewardship model}

One potentially useful framework that has been developed is the Nuffield Council on Bioethics stewardship model of public health, which seeks to clarify ethical boundaries for public health interventions. It recommends that public health programs: not attempt to coerce adults to lead healthy lives; minimise introduction of interventions without consent; and minimise interventions that are unduly intrusive and in conflict with personal values. ${ }^{18,19}$ The stewardship model also incorporates an intervention ladder, ranging from 'no intervention' to 'eliminating choice' altogether, as follows: ${ }^{19}$

- Eliminate choice - e.g. compulsory isolation of patients with infectious diseases

- Restrict choice - e.g. removing unhealthy ingredients from foods, or unhealthy foods from shops or restaurants

- Guide choice through disincentives - e.g. through taxes on cigarettes, or by discouraging the use of cars in inner cities through charging schemes or limitations of parking spaces

- Guide choices through incentives - e.g. offering tax breaks for the purchase of bicycles that are used as a means of travelling to work

- Guide choices through changing the default policy e.g. in a restaurant, instead of providing chips as a standard side dish (with healthier options available), menus could be changed to provide a more healthy option as standard (with chips as an available option)

- Enable choice - e.g. by offering participation in a National Health Service (NHS) stop smoking program, building cycle lanes or providing free fruit in schools.

- Provide information - e.g. campaigns to encourage people to walk more or eat five portions of fruit and vegetables per day

- Do nothing or simply monitor the current situation.

The stewardship model of public health emphasises the state's responsibility to address the needs of both individuals and the population, but is careful to articulate what the practical limits of this responsibility might be and how such limits might be identified. ${ }^{18}$

In light of the currently uncertain evidence about the longterm impact of overweight and obesity interventions, and identifiable ethical questions in this area, it would be useful to conduct an analysis of the current obesity prevention strategy in this country according to the stewardship model. This analysis would identify where Australia's obesity interventions sit on the intervention ladder (from 'no intervention' to 'eliminating choice' altogether) and what their associated impact is on health choices. 
The analysis could provide information about whether any of the approaches exceed acceptable intervention constraints or limits, and if they do, what action should be taken and who should be involved in that action.

\section{Conclusions}

The available evidence clearly demonstrates that obesity is a significant public health issue in Australia and globally, and as such requires a comprehensive prevention response. The evidence is currently less clear about the long-term impact of both individual and population level interventions on reducing obesity and associated health outcomes, and there are indications that some interventions may have unintended consequences for individuals assessed as overweight and obese.

In seeking to justify our interventions in the lives of individuals in the name of expected population health gains, there are ethical questions that we must consider beyond the usual technical and evidentiary considerations. These ethical issues relate to the types of health identities that are permitted in society, the possible unintended consequences of preferencing certain health identities over others, and the manner in which public health policies and interventions are justified.

\section{Acknowledgments}

$\mathrm{CF}$ acknowledges the suggestions made by anonymous reviewers that helped to enhance an earlier draft. CF is supported by an NHMRC Career Development Fellowship APP1010390 (2011-14), and the Murdoch Childrens Research Institute (Victorian Government Operational Infrastructure Support Program).

\section{References}

1. Fry CL. Critical questions we should ask in a changing Australian preventative health landscape: Competing interests, intervention limits, and permissible health identities. Health Promot J Austr 2010; 21: 170-5.

2. Fry CL, Buchman DZ. Toward a lay descriptive account of identity in addiction neuroethics. In: Carter A, Hall W, Illes J, editors. Addiction neuroethics - the ethics of addiction neuroscience research and treatment. London: Elsevier; 2011, pp. 175-93.

3. Adams PJ. Fragmented intimacy: addiction in a social world. New York: Springer; 2008.

4. Sulkunen P, Rantala K, Määttä M. The ethics of not taking a stand: dilemmas of drug and alcohol prevention in a consumer society - a case study. Int J Drug Policy 2004; 15 : 427-34. doi:10.1016/j.drugpo.2004.08.004

5. Australian Bureau of Statistics. National Health Survey: Lifestyle and Health, 1989-90. Catalogue No. 4366.0. Canberra: Australian Bureau of Statistics; 1991.
6. Australian Bureau of Statistics. National Health Survey: Summary of Results, 2007-08. Catalogue No. 4364.0. Canberra: Australian Bureau of Statistics; 2009.

7. Australian Government. Obesity in Australia: a need for urgent action. Technical report no 1. Prepared for the National Preventative Health Taskforce by the Obesity Working Group; 2009. Available at: http://www.preventativehealth.org.au/ internet/preventativehealth/publishing.nsf/Content/ tech-obesity. (Cited 1 December 2011).

8. Meetoo D. The imperative of human obesity: an ethical reflection. Br J Nurs 2010; 19: 563-8.

9. ten Have M, de Beaufort ID, Teixeira PJ, Mackenbach JP, van der Heide A. Ethics and prevention of overweight and obesity: an inventory. Obes Rev 2011; 12(9): 669-79.

10. Egger G. Obesity and chronic disease: have we missed the point? Med J Aust 2011; 195: 377. doi:10.5694/mja11.11144

11. Allender S, Gleeson E, Crammond B, Sacks G, Lawrence M, Peeters A et al. Policy change to create supportive environments for physical activity and healthy eating: which options are the most realistic for local government? Health Promot Int 2011; Mar 18.

12. Cochrane Library. Prevention of obesity. Special Collection: Published 7 December 2011. Available at: http://www. thecochranelibrary.com/details/collection/1417657/ Prevention-of-obesity.html (Cited 9 December 2011).

13. Thomas SL, Lewis S, Hyde J, Castle D, Komesaroff P. "The solution needs to be complex". Obese adults' attitudes about the effectiveness of individual and population based interventions for obesity. BMC Public Health 2010; 10: 420. doi:10.1186/ 1471-2458-10-420

14. Saarni SI, Anttila H, Saarni SE, Mustajoki P, Koivukangas V, Ikonen TS et al. Ethical issues of obesity surgery-a health technology assessment. Obes Surg 2011; Apr 10.

15. Espinel PT. King L. A framework for monitoring overweight and obesity in NSW. Sydney: NSW Department of Health and the Physical Activity Nutrition Obesity Research Group; 2009.

16. Peckham S, Hann A. Constructing the obesity epidemic: loose science, money and public health. In: Peckham S, Hann A, editors. Public Health Ethics and Practice. Bristol: The Policy Press; 2010.

17. Wickins-Drazilova D, Williams G. IDEFICS Consortium. The ethics of evaluating obesity intervention studies on children. Int J Obes (Lond) 2011; 35(Suppl 1): S24-9. doi:10.1038/ ijo.2011.32

18. Nuffield Council on Bioethics. Public health: ethical issues. London: Nuffield Council on Bioethics; 2007. Available at: http://www.nuffieldbioethics.org/public-health (Cited 9 December 2011).

19. Calman K. Beyond the 'nanny state': Stewardship and public health. Public Health 2009; 123(1): e6-10. doi:10.1016/ j.puhe.2008.10.025 